\title{
Gorlin-Goltz syndrome - A case Report
}

\author{
Amol Karagir ${ }^{1}$, Kaushal Shah ${ }^{2}$, Sampda Kanitkar ${ }^{3}$, Rajesh Koppikar ${ }^{4}$ \\ ${ }^{1,2}$ (Department of Oral Medicine \& Radiology, Bharati Vidyapeeth Deemed University dental college, Sangli, \\ Maharashtra, India.) \\ ${ }^{3}$ (Department of Oral Pathology, Bharati Vidyapeeth Deemed University dental college, Sangli, Maharashtra, \\ India) \\ ${ }^{4}$ (Department of Periodontology, Bharati Vidyapeeth Deemed University dental college, Sangli, Maharashtra, \\ India)
}

\begin{abstract}
Gorlin-Goltz syndrome is a rare autosomal dominant disorder that involves multiple organ systems, including the skin, skeleton and jaws. We report a case of young female with multiple odontogenic keratocysts, high arched palate, euryopia, palmer pits, solitary, pigmented nevus, areas of hyper-pigmentation in the upper eyelid of left eye, dorsal surface of hands, calcified diaphragma sellae, right $5^{\text {th }}$ bifid rib \& extensive bilamellar calcifications of the falx cerebri. Based on the combination of imaging and clinical findings the diagnosis of Gorlin-Goltz syndrome was made.

Keywords - bifid rib, calcification, Gorlin-Goltz syndrome, OKC, palmer pits.
\end{abstract}

\section{Introduction}

Gorlin-Goltz syndrome or Nevoid Basal Cell Carcinoma Syndrome (NBCCS) is a rare hereditary disorder. It is also called as the fifth phakomatosis due to the presence of multiple cutaneous, skeletal, ophthalmic and neurological abnormalities. Patients have multiple manifestations that include basal cell carcinoma, odontogenic cysts, skeletal anomalies, prognathism, calcification of tentorium and falx. These patients are predisposed to various anomalies and neoplasms. [1,2] We are discussing here the possibility that the current case is an expression of NBCCS and are briefly reviewing the features of the Gorlin-Goltz syndrome. Our case highlights the importance of the awareness of this rare syndrome especially in young people without any skin lesions. We have seen that it is useful to keep in mind the existence of the syndrome and recognize the presence of some major criteria (odontogenic cysts of the jaw or calcifications of falx cerebri and tentorium) as these are easily recognizable in CT scan of the head and neck thus establishing the diagnosis, and increasing the chances for better overall survival rates.

\section{CASE REPORT}

A young patient came to our Department of Oral Medicine \& Radiology with a complaint of slowly growing bilateral facial swelling since one year. She gave history of a large sized, unilateral facial swelling of the left side 12 years back and subsequent surgical treatment of the left mandibular tumor under general anesthesia. Excision of the tumor with drainage of pus had done on the left side of mandible. Since last one year, the swellings on both sides had spontaneously developed. The swelling on right side had grown very slowly over a period of last one year and attained the present size while the swelling on left side was observed since 3 months. Patient gave history of dull pain which was localized to the sites of swelling, which preceded and lasted for 10-15 days after which there had been no such episode. Since then, patient gave history of restricted mouth opening associated with onset of swelling. Patient also gave history of intermittent intra-oral yellowish, red discharge from the left side mucosa, leaving behind a metallic taste for 5-7 days. Patient neither gave history of swelling appearing elsewhere in the body nor other changes such as ulcerations, inflammation, paraesthesia. There was no evidence of loss of body weight associated with the appearance of swelling. She gave history of irregular \& painful menstrual cycles. Otherwise there was no relevant medical history. Patient was not addicted to any deleterious habits. There was no relevant family history of similar and other types of illnesses.

\subsection{Clinical examinations}

There was a facial swelling (Fig.1\&2) bilaterally in the pre-auricular region overlying the anatomic areas of the ramus and body of the mandible causing significant asymmetry. The swelling on the left side measured approximately $4.8 \times 5 \mathrm{~cm}$ and the right side measured approximately $4.8 \times 4.5 \mathrm{~cm}$ in dimensions. Swellings on both right and left sides were extended superiorly till infra-orbital margins, inferiorly till inferior border of the mandible, anteriorly till $1-2 \mathrm{~cm}$ distal to the corner of mouth and posteriorly upto pre-auricular region. The sub-mental and mental region were spared. The edge or the margin of the swelling on both sides was smooth on palpation however, was not very distinct. The overlying skin was normal in color. On palpation, 
the entire surface of the swelling was smooth \& uniformly bony hard in consistency throughout its periphery. However, less hardness was felt at the centre. The temperature in the localized area of swelling was found to be normal and similar on both sides. The characteristic fluctuation was elicited, that was more appreciable on the right side. Mild hypertelorism i.e. Euryopia was present, canthal index on measurement of inner and outer canthal distance was $38.09 \mathrm{~mm}$. There was an extra-oral scar of suture line (Fig.3) suggestive of previous operation on the left side along the inferior border of mandible proceeding towards the midline. There was restricted mouth opening; inter-incisal distance on measurement was 30mm.(Fig.4) No lymphadenopathy was noted. Salivary glands and Temporomandibular joints did not show any abnormalities. On intra-oral examination, (Fig.5) expansion of the buccal and lingual cortical plates with an egg-shell crackling at the anterior portion of the ascending ramus was noted in the right and left posterior region of the mandibular arch. Overlying mucosa was normal. The swelling on both sides was tender, non-reducible, non-compressible and non-pulsatile suggestive of bony lesion. 18, 28, 38, 43, 47, 48 teeth were missing. Over retained deciduous 53 was noted. Root pieces with 17, 26, 36, 46 were found. No mobility or pain on percussion of the associated teeth was noted. Maxillo-facial examination revealed an area of hyper-pigmentation on the upper left eyelid (Fig.6) $\&$ on the dorsal surface overlying the first inter phalangeal joint of all fingers. (Fig.7) A single mole (Fig.8) also referred as the pigmented nevus, blue in color, smooth, non-hairy in appearance, and $0.5-1 \mathrm{~mm}$ in diameter was seen on the right side of upper trunk region. On examination of the palms, multiple areas of pin-point sized pits i.e. palmar pits, on both the hands were observed. (Fig.9)

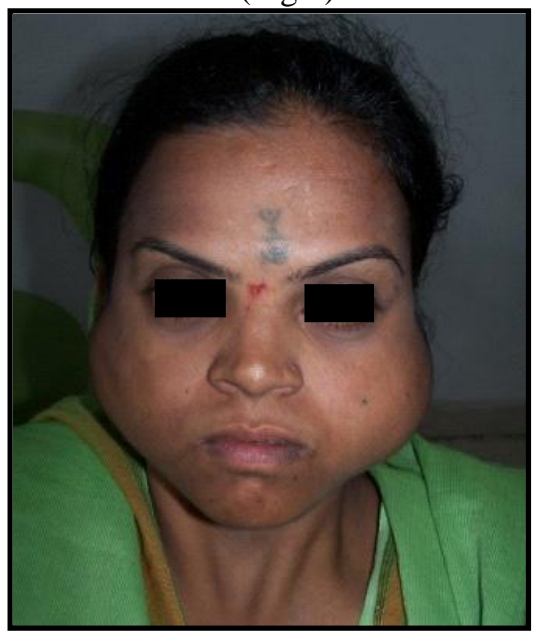

Fig.1 Pre - Operative frontal profile of patient

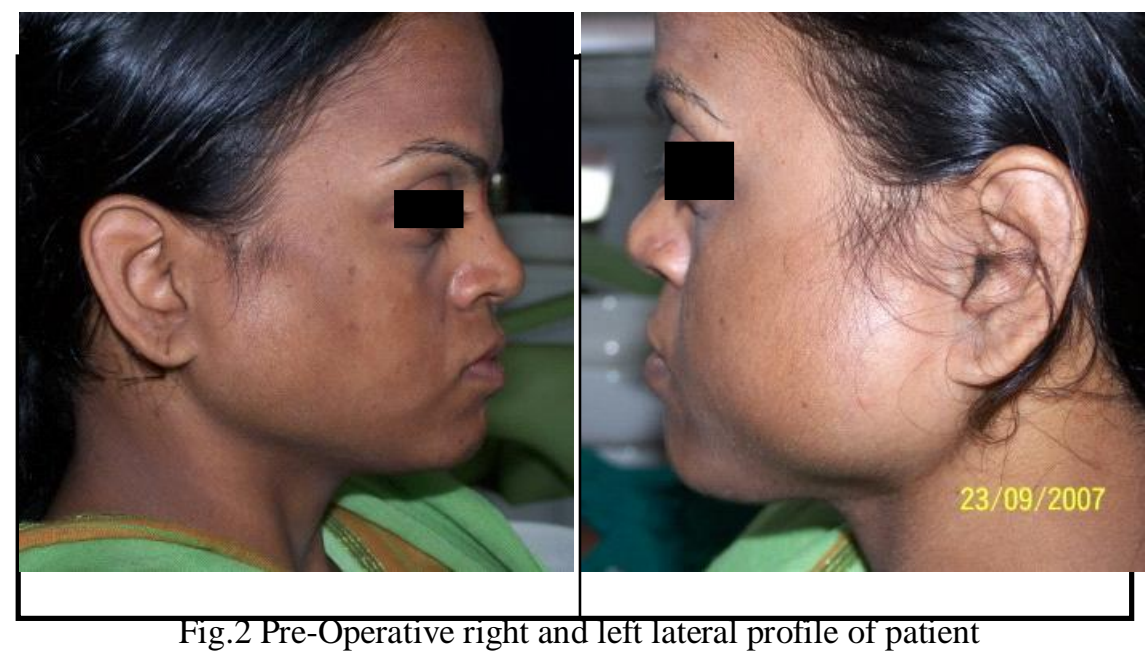




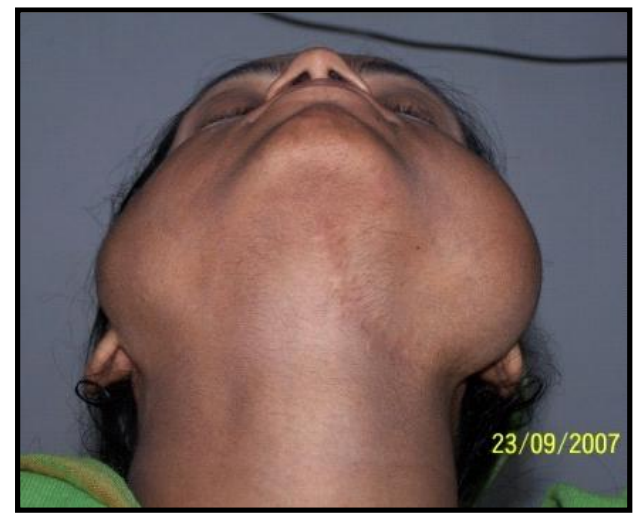

Fig.3 Inferior extra-oral profile

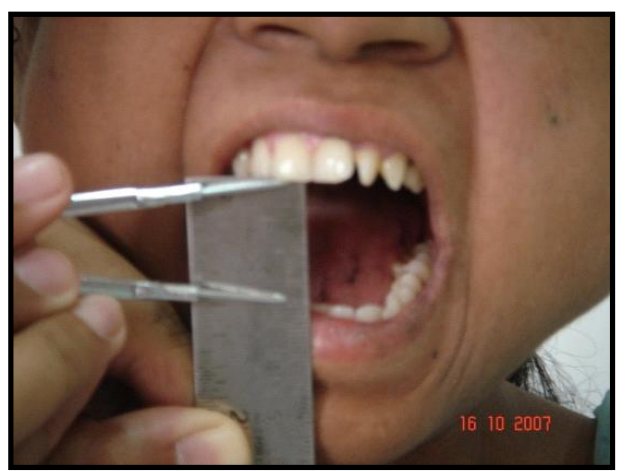

Fig.4 Extra-oral open mouth view

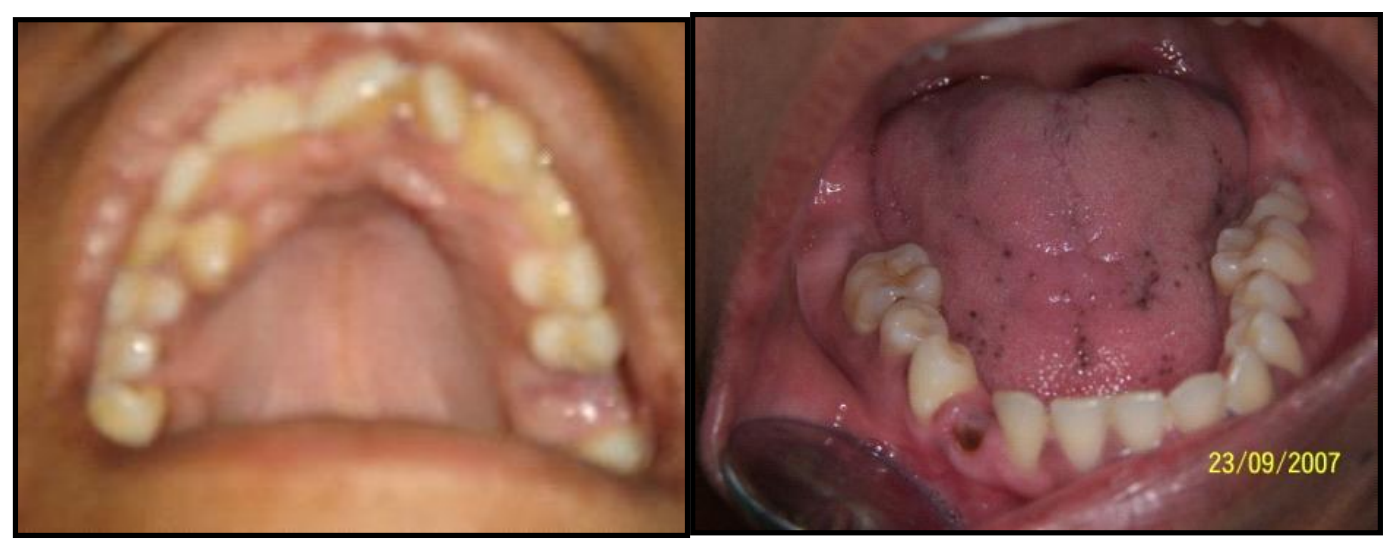

Fig.5 Intraoral views

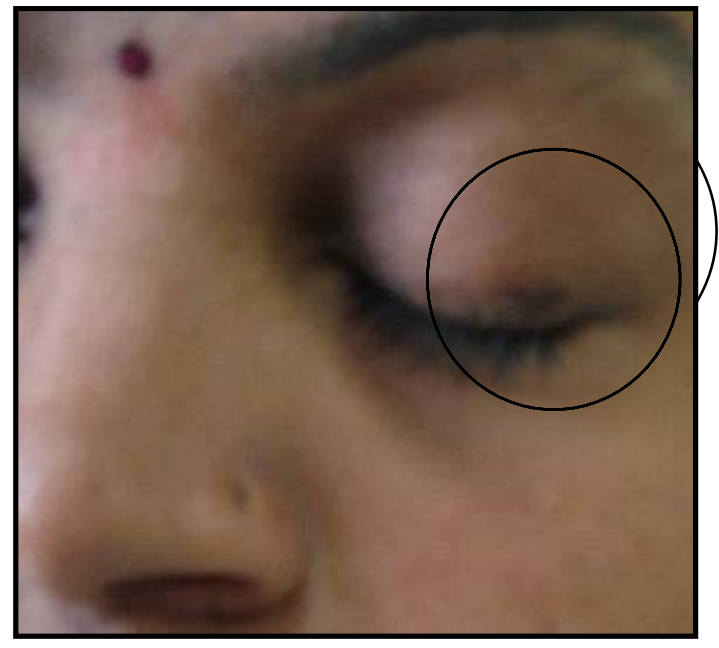


Fig.6 Close-up of left eyelid

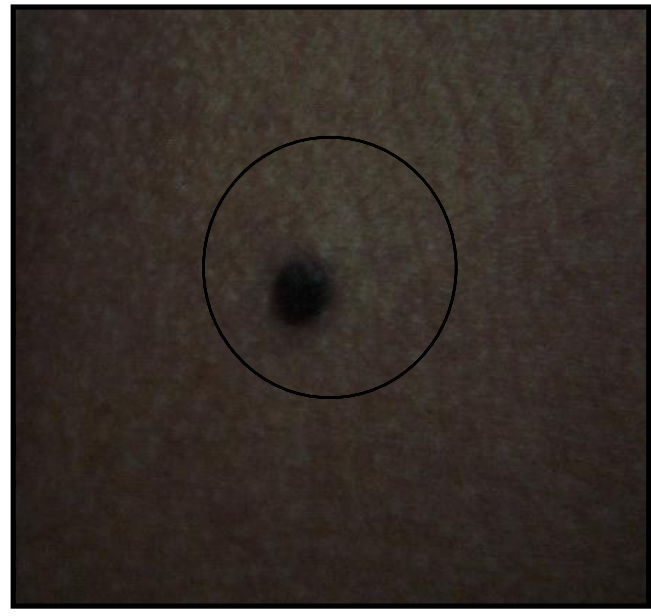

Fig.7 Dorsal surface of both hands

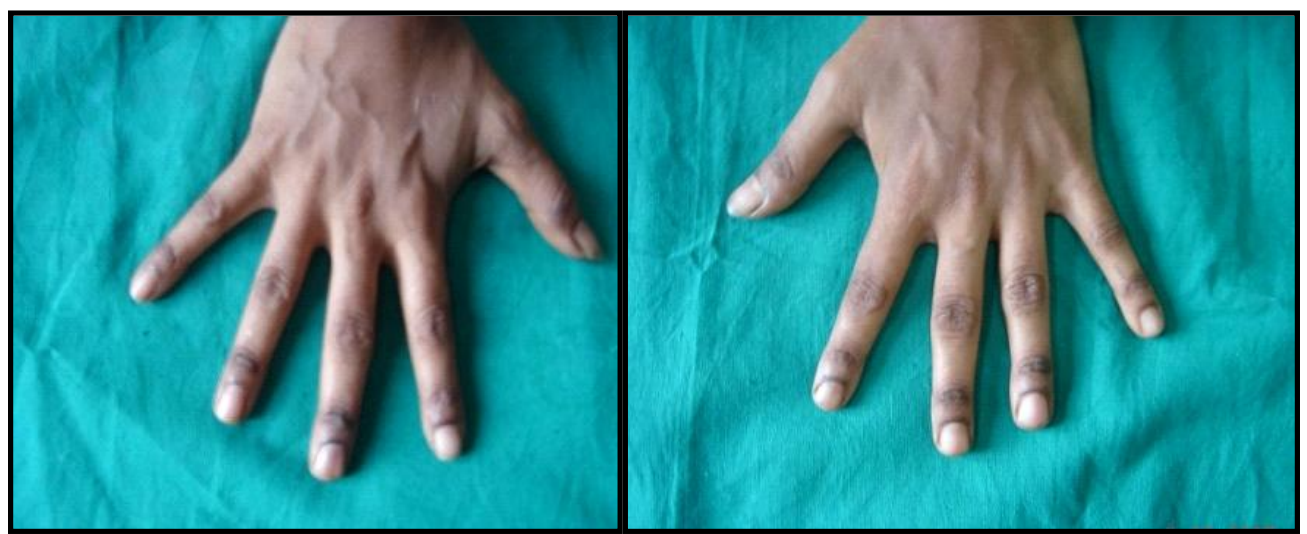

Fig.8 Close-up of right upper trunk region

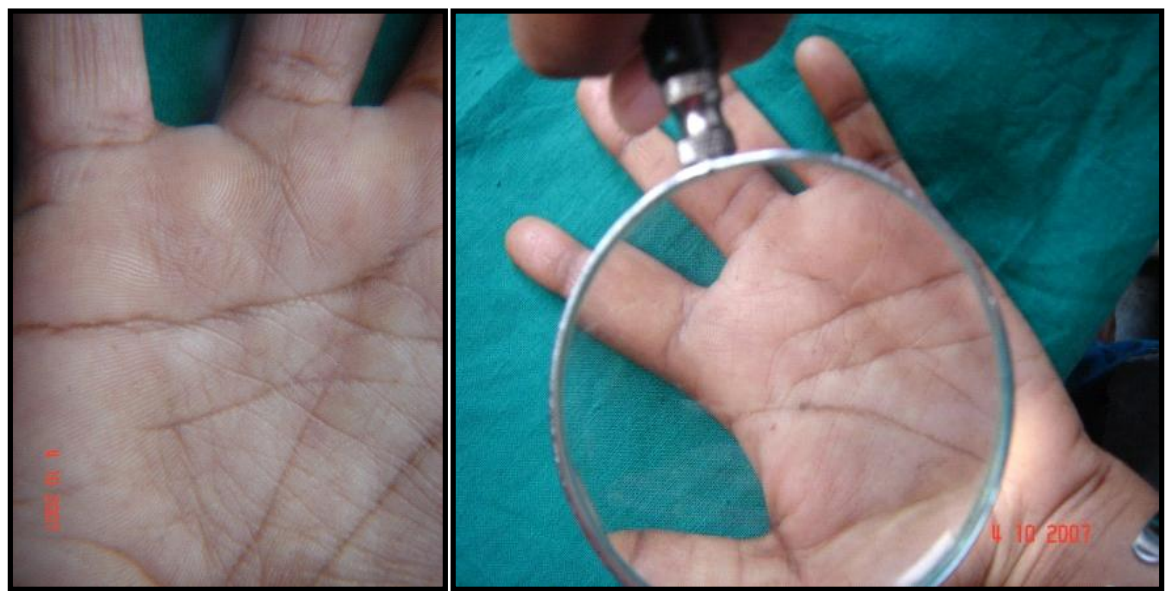

Fig.9 Close-up of palm.

\subsection{Radiographic Examinations}

Orthopantomograph(OPG) (Fig.10) and Lateral oblique projections (Fig.11) showed bilateral, multiple, well defined areas of radiolucency surrounded by well corticated, scalloped radiopaque borders contributing to the multilocular appearance. The right side of the mandible showed an extensive area of radiolucency extending from distal and inferior to the $1^{\text {st }}$ molar, upto the coronoid process involving the external oblique ridge, angle of mandible, posterior border of mandible and the entire ascending ramus in both vertical and horizontal dimensions. Thinning of the anterior and posterior cortical borders of the ramus was seen. Multiple, thin curved septae were seen within the radiolucency giving it a multilocular appearance with a smooth periphery and 
scalloped margins. A solitary, circular, area of radiolucency surrounded by a radiopaque, corticated border was seen between the roots of lower right $1^{\text {st }}$ and $2^{\text {nd }}$ premolar. The left side of the mandible showed an extensive area of radiolucency extending from distal to the $2^{\text {nd }}$ molar upto the coronoid process and to the head of the condyle of mandible and ascending ramus. Thinning of the cortical borders with a smooth periphery and haziness was seen within with faint, curve septae, giving a multilocular appearance. There was prominent antegonial notch of mandible. The radiolucency extended to involve the inferior border of mandible, showing an area of discontinuity suggestive of a pathologic fracture. The right side maxilla showed radiolucent coronoid process and a solitary area of radiolucency at the apex of the root piece of second molar with faint cortication. The left side maxilla showed radiolucency extending between the roots of $2^{\text {nd }}$ premolar upto the mesial of the $2^{\text {nd }}$ molar surrounded by a hyperostotic border. There was an impacted canine in right, lower quadrant and all $3^{\text {rd }}$ molars were missing. Root pieces of 17 and 26 were evident. No displacement of teeth was noted. All other anatomical structures appeared normal. CT images (Fig.12) revealed abnormal multilocular, expansile, cystic lesions with a bony sclerotic margin and bulging of the bony cortex involving bilateral hemi-mandible. The lesions were involving the ramus of mandible with scalloping and pressure expansion of the alveolar cortices of the hemi-mandible in the region of molar teeth. The lesion on the right side led to scalloping of the posterior wall of the right maxillary sinus. There was no extension into the right maxillary antrum noted. A polyp was seen in the right maxillary antrum. Right maxillary sinus was reduced in size because of encroaching polyp. Bilateral middle turbinates were pneumatised. An area of solitary swelling was seen in between roots of mandibular right 1st and 2nd pre-molars. The area of solitary swelling in between the mandibular pre-molars of the right side was seen. CT of the Brain (Fig.13) demonstrated calcifications. Chest radiograph revealed bifid $5^{\text {th }}$ rib. (Fig.14)

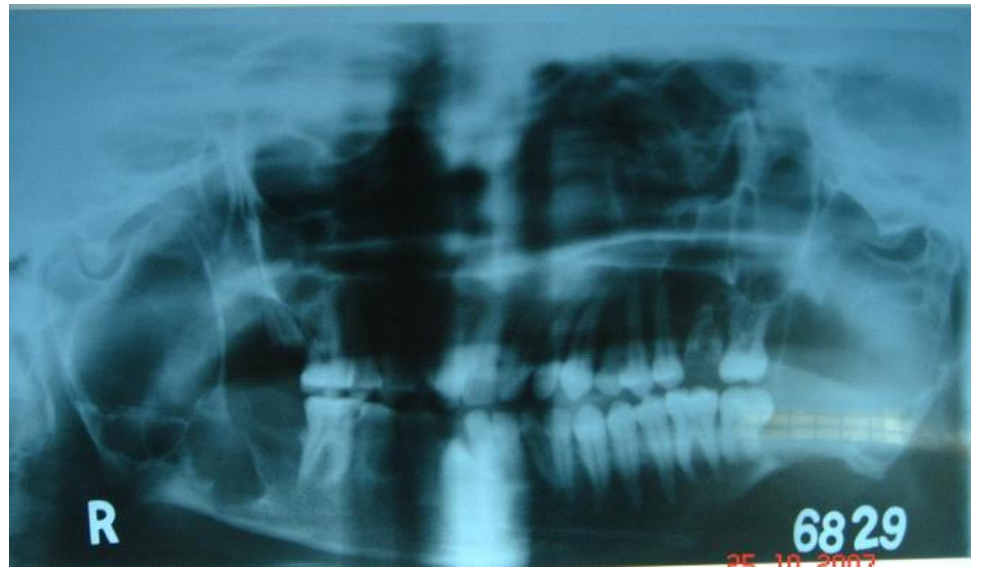

Fig.10 Orthopantomograph

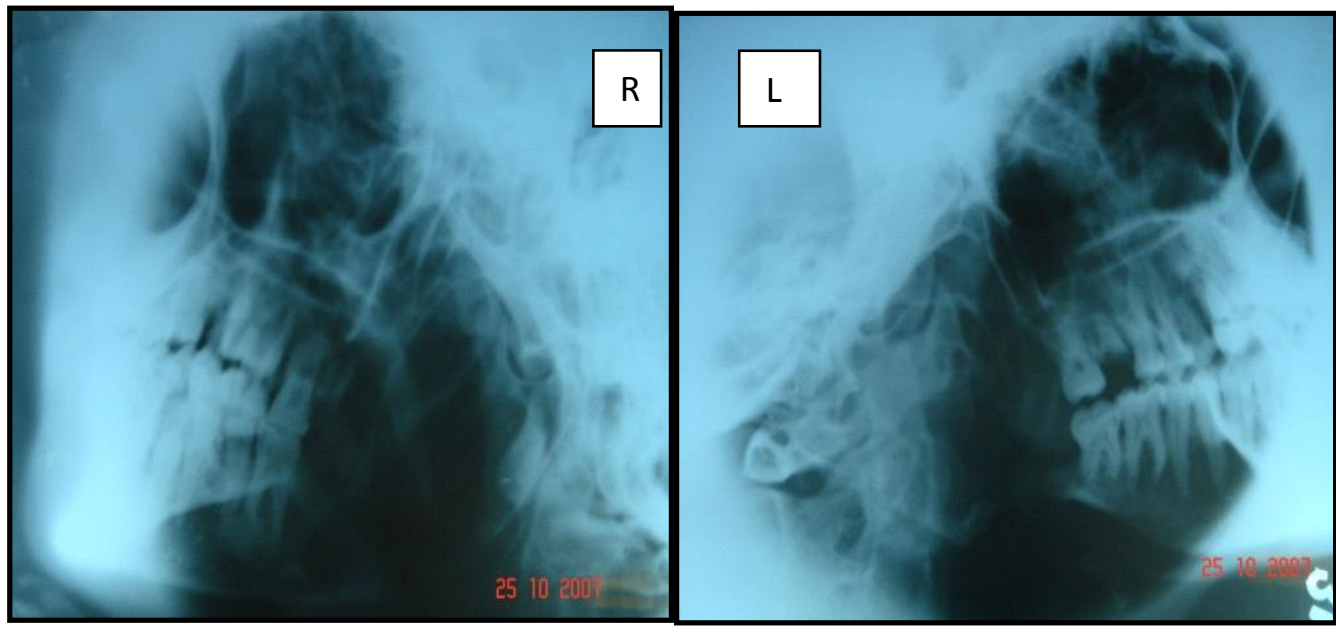

Fig.11 Mandibular lateral oblique projections (Right \& left) 


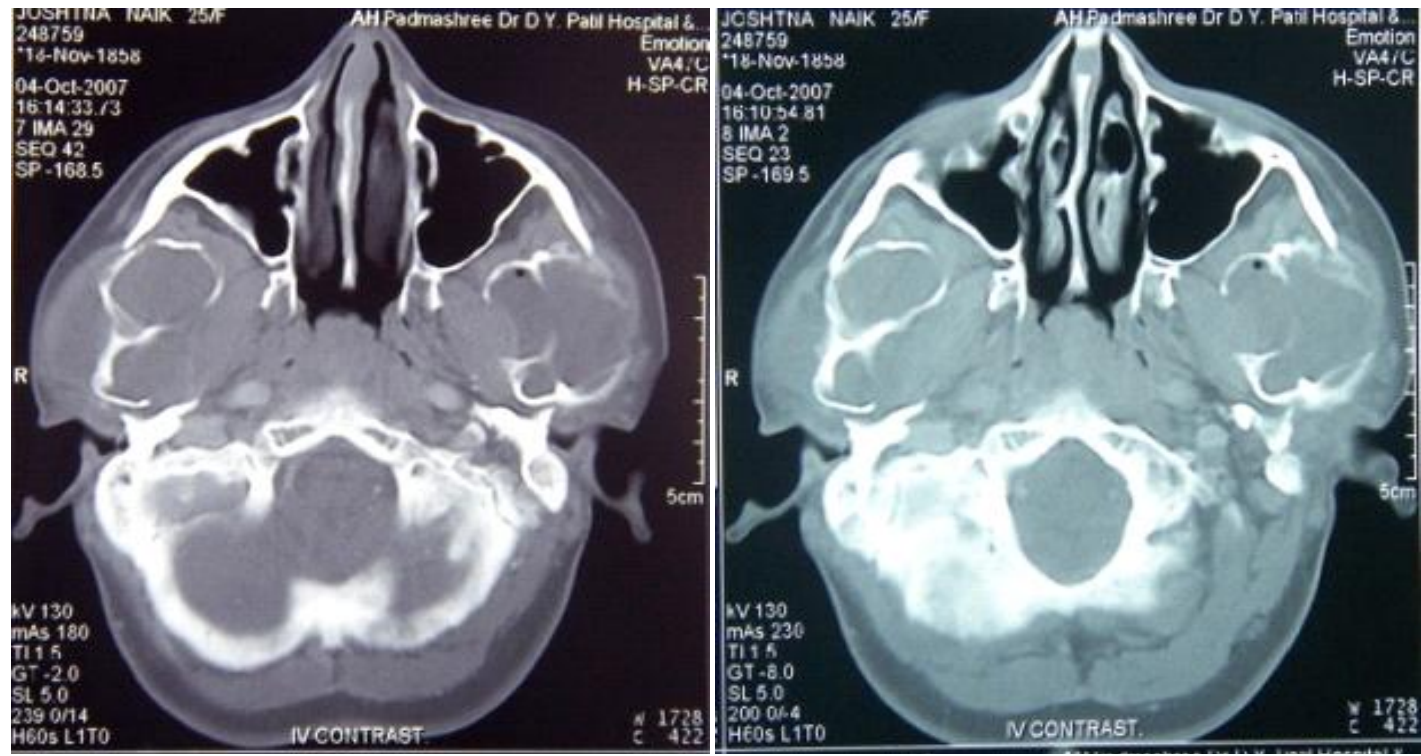

Fig. 12 Axial CT views of mandible

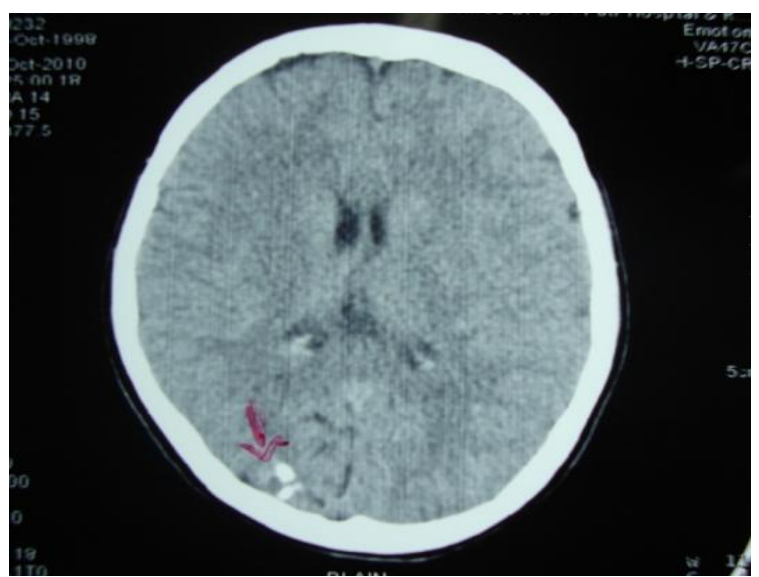

Fig.13 CT of the Brain demonstrated calcifications

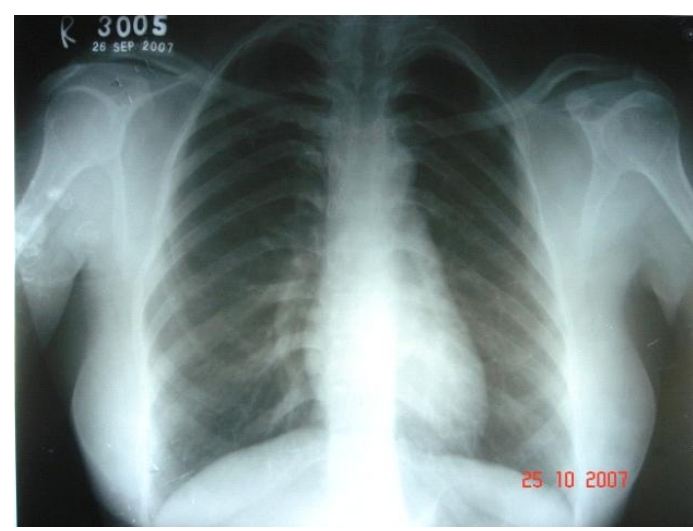

Fig.14 X-Ray Chest

\subsection{Histopathological Examinations}

FNAC was performed from swelling on right side \& aspirate was yellowish in colour and thin in consistency. It showed plenty of inflammatory cells with cholesterol crystals. Incisional biopsy was done from right and left retromandibular region \& histopathologically (Fig.15) there were a characteristic 6-8 basal cell layer thickness of stratified squamous epithelium thrown into corrugations indicative of odontogenic keratocyst. 


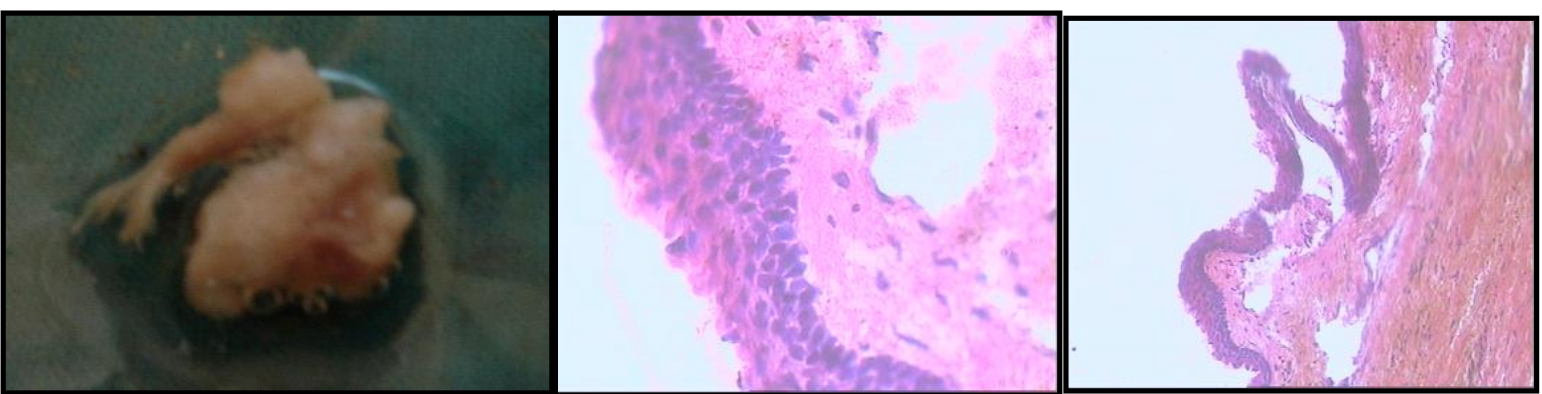

Fig.15 Surgical specimen and Photomicrographs

\subsection{Management}

Considering the appearance of multiple OKC bilaterally at the young age and a history of recurrence, necessitated, evaluation of the patient for an association of a syndrome, the most probable being Nevoid Basal Cell Carcinoma Syndrome also called Gorlin-Goltz Syndrome. This syndrome has variable expressivity, and shows craniofacial features, dermatological, skeletal, multiple OKC of jaw, central nervous system \& opthalmologic involvement.

Patient was referred to the Department of Oral \& Maxillofacial Surgery. Decompression and arch bar stabilization of both maxilla and mandible along with instillation of Carnoy's solution as a fixative agent for shrinkage of the lining epithelium was performed. Later surgical enucleation was carried out under general anesthesia. (Fig.16)
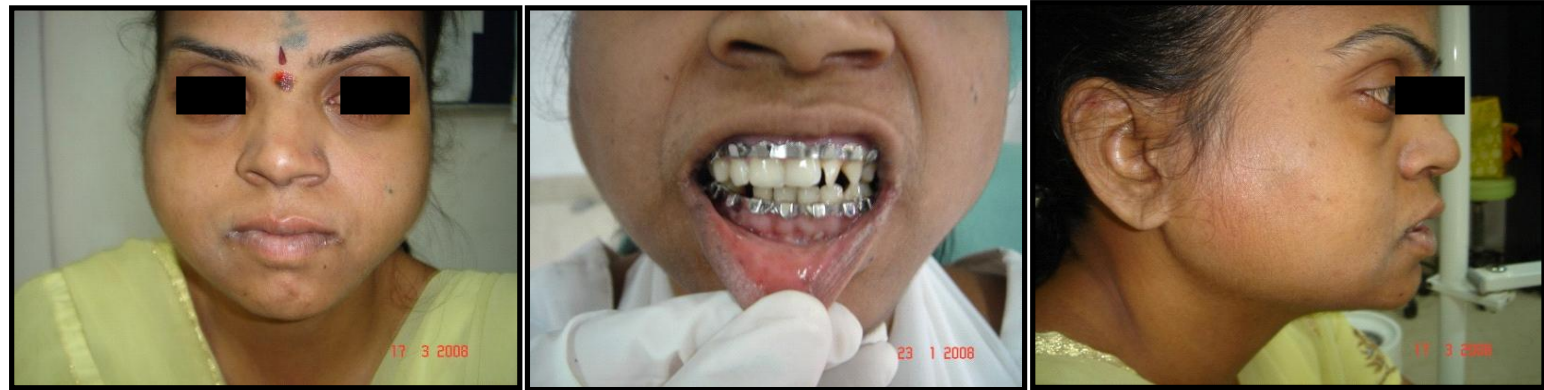

Fig.16 Post - operative photographs

\section{Discussion}

Gorlin-Goltz syndrome also known as Nevoid Basal Cell Carcinoma Syndrome was described for the first time in 1894 by Jarisch and White. The disease is an autosomal dominant disorder mainly characterized by the presence of multiple basal cell carcinomas, odontogenic keratocysts of the jaw and palmar pits [3,4]. The estimated prevalence varies from $1 / 57000$ to $1 / 256000$.[5] It is seen in males and females equally. [6] This syndrome is due to tumor suppressor gene mutation in the long arm of chromosome 9 (q22.3-q31). Approximately, 35-50\% of cases are due to new mutations.[7]

Evans et al[8] first established major and minor criteria for diagnosis of this rare entity, later modified by Kimonis et al[9]. Although these criteria are not absolute, they can help guiding the clinician's laboratory evaluation for both diagnostic purposes and routine follow up.

Major criteria consist of:

I. More than two basal cell carcinomas or one in patient less than 20 years old

II. Odontogenic keratocysts of the jaw

III. Three or more palmar or plantar pits

IV. Bilamellar calcifications of falx cerebri and tentorium

V. Bifid or fused, or markedly splayed ribs

VI. First-degree relative with Gorlin-Goltz syndrome.

Minor criteria consist of:

I. Macrocephaly,

II. Congenital anomalies (cleft lip or palate, frontal bossing, coarse facies, and moderate or severe hypertelorism)

III. Other skeletal anomalies (Sprengel deformity, marked pectus deformity, and marked syndactyly of the digits)

IV. Radiologic anomalies (such as bridging of the sella turcica, vertebral anomalies, modelling defects of the hands and feet, or flame-shaped lucencies of the hands and the feet) ${ }^{9}$ 
V. Ovarian fibroma or myeloblastoma.

2 major criteria or 1 major and 2 minor criteria are obligatory in order to diagnose Gorlin-Goltz syndrome[10].

In our case, two major criteria - odontogenic keratocysts of the jaw and calcification of falx-cerebri and tentorium and one minor criteria skeletal anomaly-bifid vertebra were detected. Other recognizable features of the syndrome were high arched palate, euryopia (mild hypertelorism), canthal index of 38.09, palmer pits, solitary, pigmented nevus (mole), areas of hyper-pigmentation in the upper eyelid of left eye, dorsal surface of hands \& calcified diaphragma sellae (bridged Sella, fused clinoids), Hence diagnosis was made as Gorlin-Goltz syndrome.

\section{Conclusion}

Our case highlights the importance of the awareness of this rare syndrome, as in young patients without any skin lesions, Gorlin-Goltz syndrome can go unnoticed. It is important to recognize the presence of some major criteria (odontogenic cysts at the jaw or calcifications of falx cerebri and tentorium) as these are easily recognizable in routine OPG or CT scan of the head and neck thus establishing the diagnosis. Periodic abdomino-pelvic ultrasound and brain MRI are recommended for early detection of malignancies. Once the diagnosis is established, genetic counselling of all family members is recommended. Frequent follow-ups are necessary, increasing the chances for better overall survival rates.

\section{References}

[1] Gailani MR, Bale SJ, Leffell DJ, et al. Developmental defects in Gorlin syndrome related to a putative tumor suppressor gene on chromosome. Cell 1992;69(1):111-117.

[2] Lindeboom JA, Kroon FH, de Vires J, van den Akker HP. Multiple recurrent and de novo odontogenic keratocysts associated with oral-facial-digital syndrome. Oral Surg Oral Med Oral Pathol Oral Radiol Endod 2003;95(4):458-462.

[3] Kolm I, Puig S, Iranzo P, Malvehy J. Dermoscopy in Gorlin-Goltz syndrome. Dermatol Surg. 2006;32(6):847-851.

[4] Rozylo-Kalinowska I, Rozylo TK. Odontogenic keratocyst in Gorlin-Goltz syndrome. Ann Univ Mariae Curie Sklodowska. 2002;57(2):79-85.

[5] Lo ML. Nevoid basal cell carcinoma syndrome (Gorlin syndrome). Orphanet J Rare Dis 2008; 3:32.

[6] Kimonis VE, Goldstein AM, Pastakia B, Yang ML, Kase R, DiGiovanna JJ, et al. Clinical manifestations in 105 persons with nevoid basal cell carcinoma syndrome. Am J Med Genet 1997;69(3):299-308.

[7] Kalogeropoulou C, Zampakis P, Kazantzi S, Kraniotis P, Mastronikolis NS. Gorlin-Goltz syndrome: Incidental finding on routine CT scan following car accident. Cases J 2009;2:9087.

[8] Evans DG, Ladusans EJ, Rimmer S, Burnell LD, Thakker N, Farndon PA: Complications of the nevoid basal cell carcinoma syndrome: results of a population based study. J Med Genet 1993;30:460-464.

[9] Kimonis VE, Mehta SG, Digiovanna JJ, Bale SJ, Pastakia B: Radiological features in 82 patients with nevoid basal cell carcinoma (NBCC or Gorlin) syndrome. Genet Med 2004;6(6):495-502.

[10] Manfredi M., Vescovi P., Bonanini M., Porter S.: Nevoid basal cell carcinoma syndrome : A review of the literature. Int J. Oral Maxillofac. Surg, 2004;33:117-124 